\title{
Prevention of long-term sickness absence and major depression in high-risk employees: a randomised controlled trial
}

Citation for published version (APA):

Lexis, M. A. S., Jansen, N. W. H., Huibers, M. J. H., van Amelsvoort, L. G. P. M., Berkouwer, A., Tijn A Ton, G., van den Brandt, P. A., \& Kant, IJ. (2011). Prevention of long-term sickness absence and major depression in high-risk employees: a randomised controlled trial. Occupational and Environmental Medicine, 68(6), 400-407. https://doi.org/10.1136/oem.2010.057877

Document status and date:

Published: 01/06/2011

DOI:

10.1136/oem.2010.057877

Document Version:

Publisher's PDF, also known as Version of record

\section{Please check the document version of this publication:}

- A submitted manuscript is the version of the article upon submission and before peer-review. There can be important differences between the submitted version and the official published version of record. People interested in the research are advised to contact the author for the final version of the publication, or visit the DOI to the publisher's website.

- The final author version and the galley proof are versions of the publication after peer review.

- The final published version features the final layout of the paper including the volume, issue and page numbers.

Link to publication

\footnotetext{
General rights rights.

- You may freely distribute the URL identifying the publication in the public portal. please follow below link for the End User Agreement:

www.umlib.nl/taverne-license

Take down policy

If you believe that this document breaches copyright please contact us at:

repository@maastrichtuniversity.nl

providing details and we will investigate your claim.
}

Copyright and moral rights for the publications made accessible in the public portal are retained by the authors and/or other copyright owners and it is a condition of accessing publications that users recognise and abide by the legal requirements associated with these

- Users may download and print one copy of any publication from the public portal for the purpose of private study or research.

- You may not further distribute the material or use it for any profit-making activity or commercial gain

If the publication is distributed under the terms of Article $25 \mathrm{fa}$ of the Dutch Copyright Act, indicated by the "Taverne" license above, 


\title{
Prevention of long-term sickness absence and major depression in high-risk employees: a randomised controlled trial
}

\author{
Monique A S Lexis, ${ }^{1}$ Nicole W H Jansen, ${ }^{1}$ Marcus J H Huibers, ${ }^{2}$ \\ Ludovic G P M van Amelsvoort, ${ }^{1}$ Ate Berkouwer, ${ }^{3}$ Gladys Tjin A Ton, ${ }^{3}$ \\ Piet $A$ van den Brandt, ${ }^{1}$ IJmert Kant ${ }^{1}$
}

${ }^{1}$ CAPHRI School for Public Health and Primary Care, Department of Epidemiology, Faculty of Health, Medicine and Life Sciences, Maastricht University, Maastricht, The Netherlands

${ }^{2}$ Department of Clinical Psychological Science, Faculty of Psychology, Maastricht University, Maastricht, The Netherlands

${ }^{3}$ Occupational Health Services 'Beter' (ABN AMRO Arbo Services BV), Amsterdam, The Netherlands

\section{Correspondence to}

Miss Monique Lexis, CAPHRI

School for Public Health and Primary Care, Maastricht University, Department of Epidemiology, PO Box 616, 6200

MD Maastricht, The

Netherlands;

monique.lexis@epid.unimaas.nl

Accepted 11 August 2010 Published Online First

5 October 2010

\section{ABSTRACT}

Objectives To examine the efficacy of early intervention on the prevention of long-term sickness absence and major depression among employees at high risk of future sickness absence and with mild to severe depressive complaints.

Methods Randomised controlled trial conducted among employees working in an office environment. 139 employees were identified both at high risk of future sickness absence and with mild to severe depressive complaints through screening. Subsequently, they were randomly assigned to the intervention group $(n=69)$ or the control group $(n=70)$. Objective sickness absence was analysed at 12 and 18 months of follow-up. Depressive complaints were assessed by the Beck Depression Inventory (BDI-II) at baseline, and at 6 and 12 months of follow-up.

Results Intention-to-treat analyses showed a significant difference in total sickness absence duration between the intervention (27.5 calendar days (SD 44.7)) and control group (50.8 days (SD 75.8)) over 12 months of follow-up, a reduction of $46 \%(p=0.017)$. The intervention group showed a non-significantly lower proportion of long-term sickness absence spells compared with the control group ( $p=0.127)$. Statistically significant and clinically relevant differences in depressive complaints were found after both 6 months $(p=0.001)$ and 12 months $(p=0.005)$ of follow-up, in favour of the intervention group. Relative risk reductions (RRR) were $19.2 \%$ and $19.8 \%$ respectively. Sickness absence data were available for all participants over 18 months of follow-up. Questionnaire data were available for 99 (at 6 months) and 90 participants (at 12 months). No adverse events or side effects occurred. Conclusions Early intervention in employees with mild to severe depressive complaints and high risk of future long-term sickness absence proved to be effective in preventing/reducing both sickness absence and depressive complaints.

\section{INTRODUCTION}

Mental health problems are highly prevalent in the labour force and constitute a source of marked distress and social impairment for the employee. ${ }^{12}$ Major depression is considered to be one of the more severe disorders, making up a substantial part of the mental health problems. ${ }^{3}$ Recent studies showed that depressive complaints are also prevalent in the working population on a relatively mild level. ${ }^{45}$ Over

\section{What this paper adds}

- Work rehabilitation in case of sickness absence due to mental health complaints remains very difficult, and symptom reduction does not necessarily lead to work resumption.

- A previous study on a preventive strategy aimed at early intervention among employees identified at high risk of future sickness absence proved effective in the prevention of long-term sickness absence.

- Depressive complaints are highly prevalent in the working population and are associated with future long-term sickness absence.

- Preventive intervention among employees identified both at high risk of future sickness absence and with mild to severe depressive complaints proved effective in the prevention/ reduction of long-term sickness absence and depressive complaints.

- The next step will be further implementation of the preventive strategy in the occupational health setting.

time, these depressive complaints may exacerbate and result in major depression. ${ }^{6}$ Depressive complaints are found to be often associated with work disability and long-term sickness absence and increased healthcare use. ${ }^{8}$ Work disability and especially long-term sickness absence have also increasingly been recognised as considerable public health problems, with consequences for employers and society. ${ }^{9}$ So far, work rehabilitation in case of sickness absence due to mental health complaints remains very difficult, and symptom reduction does not necessarily lead to work resumption. ${ }^{10}{ }^{11}$ Conversely, sickness absence can cause and predict depressive complaints. ${ }^{12} 13$

From an occupational healthcare perspective, before treating employees with major depression or treatment of employees who are already on sick leave, a preventive strategy aimed at prevention of major depression and long-term sickness absence through early intervention might be more effective. A prerequisite for such a strategy is the ability to identify employees at high risk of future long-term sickness absence and with mild depressive complaints. To identify employees at high risk of 
sickness absence, a screening questionnaire, called Balansmeter in Dutch, was developed in 1998. ${ }^{14}$ The Balansmeter proved to have good properties in predicting long-term sickness absence. In an additional study by Kant et al conducted in 2003, it was demonstrated that early intervention among employees at risk of sickness absence proved effective in reducing future sickness absence. The current study, including a new RCT, focused on both high risk of sickness absence and depressive complaints. It was hypothesised that early intervention is effective in preventing depressive complaints and/or future sickness absence.

Numerous studies have investigated the effectiveness of different treatments for depression. ${ }^{15} 16$ Strong evidence exists that cognitive behavioural therapy (CBT) and problem-solving therapy (PST) are effective treatments for depression. ${ }^{17-20}$ CBT and PST have also been proven effective in reducing sickness absence. ${ }^{2122}$ A new protocol specifically targeted at employees, who are identified both at high risk of sickness absence and with mild to severe depressive complaints, was developed based on CBT and PST, with the main focus on work-related problems. The aim of this RCT is to examine the efficacy of this new protocol among employees identified at high risk of long-term sickness absence and with mild to severe depressive complaints on the prevention of future long-term sickness absence and major depression.

\section{METHODS}

\section{Study design, procedure and participants}

A randomised controlled trial (RCT) was conducted among employees of a large banking company in The Netherlands. Figure 1 presents the selection process of the study. In 2007, 23973 employees received a screening questionnaire at their home address. In the invitation letter, employees were asked to provide written informed consent, which covered the usage of questionnaire data, the company data on sickness absence and the possibility of participating in the trial. In total, 9157 employees (38.2\%) responded to the questionnaire; 8892 questionnaires were suitable for analyses, and 265 were discarded due to technical reasons or because no informed consent was provided. Employees identified at risk of sickness absence and with mild to severe depressive complaints $(n=211)$ received an extensive baseline questionnaire (T0). Exclusion criteria were being (fully or partially) absent from work, pregnant or on pregnancy/maternity leave or receiving treatment by a psychologist/psychiatrist, at the time of completing the screening questionnaire. Employees who responded to the baseline questionnaire $(n=150)$ and still met the selection criteria $(n=139)$ were randomised into the intervention $(n=69)$ or the control group ( $n=70)$. Randomisation sequences were generated using computerised random number generators (block size 2) by the principal investigator (ML), based on employee personnel numbers. Company counsellors and psychologists were not blind to group allocation. However, they were only aware of participants of the intervention group. Follow-up questionnaires were sent at 6 and 12 months after randomisation to assess depressive complaints and secondary outcomes. Objective sickness absence data were assessed at 12 and 18 months of follow-up. The study was covered by the medical guidelines of the occupational health service, thereby ensuring all participants' privacy and anonymity. The study was approved by the Medical and Ethical Committee of Maastricht University (MEC 06-3-018). The study was performed according to the Declaration of Helsinki.

\section{Preventive intervention}

The intervention consisted of a psychological treatment based on the principles of PST and CBT. The main goal of the intervention, which had an individual orientated approach, was to offer guidelines to enhance problem-solving skills in order to prevent long-term sickness absence and to reduce depressive complaints and to stimulate personal well-being. The intervention was specifically developed for our target population by four experts in the field of psychology. A treatment protocol and workbooks for practical assignments were developed for the trial based on two main sources. ${ }^{23-26}$ The focus of the protocol was on employees with relatively mild complaints and who were still at work. The intervention was preventive because of its timing, treatment before sickness absence occurs and because it focused on relatively mild complaints. Therefore, the intervention consisted largely of PST. CBT/PST often consist of 10 to 12 sessions. This new intervention consisted of a basic part and a specific part. The basic part contained seven sessions of 45 min each, based on the major steps of PST. Through all sessions, principles of CBTwere applied. The seventh session consisted of an evaluation session. Since it was unknown at the start of the study if seven sessions would be sufficient for every participant, the intervention could be extended with a maximum of five sessions. In the seventh session, the psychologist and employee decided in consultation to end treatment in case the participant had recovered or to move on with the specific part of the protocol. For the specific part, the employee could indicate the subject to focus on during the sessions, such as training of social skills or cognitive restructuring. At the end of each session, homework assignments were given which were discussed in the next session. The intervention was conducted by 10 psychologists from a company consisting of a nationwide network of registered psychologists (Cenzo BV). This company regularly provides psychological healthcare for the banking company. The psychologists received 2 days of training before the study started and a 1-day booster session during the study. Participants in the control group received care as usual from the occupational health services. Care as usual when the employee asks for help included consultation with an occupational physician and, if necessary, referral to other disciplines. Care as usual in case of sickness absence included social medical counselling.

\section{Measurements \\ Screening measures \\ Risk of sickness absence}

The Balansmeter, developed in 1998 for employees working in an office work environment, was used to identify employees at high risk for future long-term sickness absence. The Balansmeter was developed and internally validated on data of the Maastricht Cohort Study and was externally validated in 2003 on a large sample of employees of the same company at which the current RCT was conducted. ${ }^{14}$ For the present study, a cut-off point with $87.9 \%$ specificity and $52.6 \%$ sensitivity in women and $87.8 \%$ and $65.1 \%$ in men was applied.

The BM includes risk of sickness absence in general, not necessarily due to depressive complaints. A second measure was included to assess depressive complaints.

\section{Depressive complaints}

Presence and severity of depressive complaints were assessed using the depression scale of the Hospital Anxiety and Depression Scale (HAD Scale). The HAD Scale is a 14-item self-report questionnaire, which was originally developed to indicate the presence and severity of both anxiety (HAD-A) and depression (HAD-D) separately. ${ }^{27}$ With respect to the cut-off values, we 
Figure 1 Flow diagram of recruitment, allocation and outcome assessment.

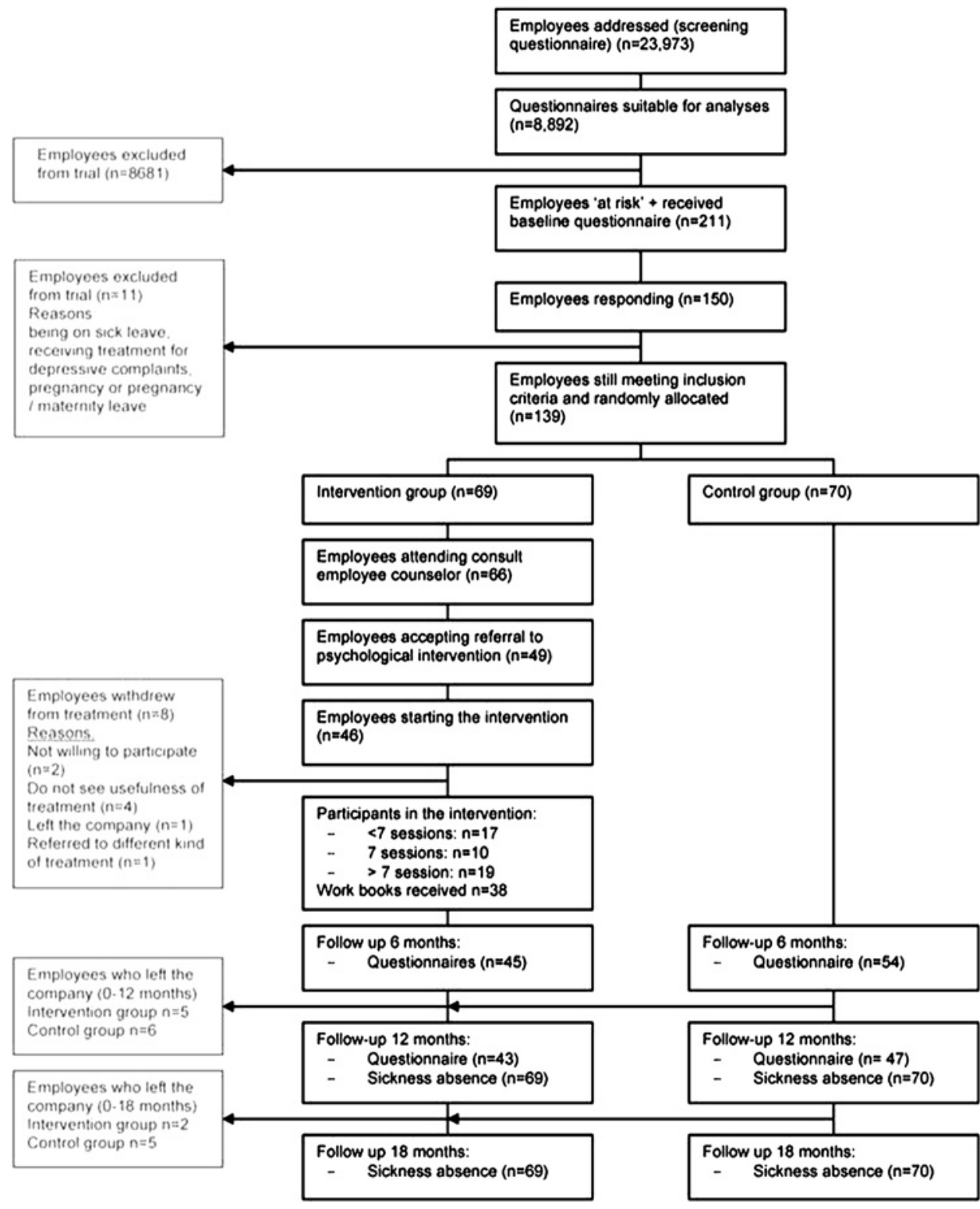

used the values suggested by Zigmond et al. ${ }^{28} \mathrm{~A}$ higher score on $\mathrm{HAD}-\mathrm{D}$ indicates more severe depressive complaints. Employees were defined as having mild to severe depressive complaints when they scored 8 points or higher on HAD-D.

\section{Primary outcome measures}

\section{Sickness absence duration}

Sickness absence duration was measured objectively (in calendar days) through record linkage on an individual level with the company registers on certified sickness absence from 2 months after employees received the screening questionnaire until 18 months of follow-up. Long-term sickness absence was defined as a sickness absence spell lasting for more than 28 consecutive days. Sickness absence was assessed for 12 and 18 months of follow-up. Measurement of sickness absence started 2 months after completing the screening questionnaire. This is in line with the development of the Balansmeter. ${ }^{14}$ Returning and processing of the questionnaires could at most take 2 months.

\section{Depressive complaints}

Depressive complaints are viewed as a continuous spectrum of complaints, ranging from no to severe depressive complaints, with major depression at the end of the spectrum. While the screening instrument included the $\mathrm{HAD}$ Scale, to assess severity of depressive complaints more extensively the commonly used Beck Depression Inventory-II (BDI-II) was used. ${ }^{29}$ For our focus on relatively mild complaints, the BDI-II was too extensive and included too 'heavy' items, on for example suicidal thoughts, to include in the screening questionnaire. We therefore included the BDI-II in the baseline questionnaire and at 6 and 12 months of follow-up. Scores on the BDI-II can range from 0 to 63 , with higher scores indicating more severe depressive symptoms. ${ }^{30}$ Scores from 0 to 13 points were defined as not/minimally depressed, 14-19 points as possibly/lightly depressed, 20-28 as moderately depressed and 29-63 points as severely depressed. ${ }^{29} 31$

\section{Secondary outcome measures}

Data on secondary outcome measures were gathered by means of self-administered questionnaires at baseline, and at 6 and 12 months of follow-up.

\section{Self-rated health}

Self-rated health was assessed with one item from the Short Form Health Survey (SF-36), widely used to measure general 
health status. ${ }^{32} 33$ 'In general, would you say your health is'. This item was scored on a five-point scale (1=excellent, $2=$ very good, 3 =good, $4=$ moderate, $5=$ bad). The Brief Symptom Inventory (BSI), a short version of the Symptom Checklist 90 (SCL-90), was used to measure general psychological distress, with higher scores indicating a higher degree of symptoms (range 0-212). ${ }^{34} 35$ Scores on HAD-D at 6 and 12 months of follow-up were defined as a secondary outcome measure.

\section{Work characteristics}

A validated Dutch version of the Job Content Questionnaire was used to measure psychological job demands, decision latitude and social support at work. ${ }^{36}$ Additional data on job insecurity and commitment were gathered with questions adapted from the Questionnaire on the Experience and Evaluation of Work (VBBA). ${ }^{37}$

\section{Cointerventions}

Cointerventions in the past 6 months, such as treatment by a general practitioner, an occupational physician, a psychologist, a psychiatrist or a company counsellor and the use of medication (including antidepressants, sleeping medication, tranquillisers, painkillers or other) were assessed by self-report.

\section{Treatment adherence}

For each participant in the intervention group, it was assessed whether the intervention was conducted according to the protocol. Adherence to the protocol was defined as being exposed to all essential predefined steps of the intervention. For the per-protocol analyses, those participants who received at least one treatment session were included, which is a rather conservative approach.

\section{Power calculation}

In calculating sample size, sickness absence was chosen as the main outcome measure of the study. Based on sickness absence data from the Maastricht Cohort Study on fatigue at work, it appeared that $60 \%$ of employees with psychological complaints were absent from work for at least 2 weeks over a period of 12 months of follow-up. ${ }^{2}$ The assumption was that the intervention would be effective by reducing this percentage to $35 \%$. Power calculation, using a two-sided significance level of $5 \%$ and a power of $80 \%$, indicated a minimum of 59 participants in each group. Taking into account a potential attrition of $15 \%$, a final sample size of 136 should be sufficient.

\section{Statistical analysis}

First, data were analysed according to the intention-to-treat principle. Difference scores on continuous outcomes were used for both sickness absence (0-12 months and 0-18 months) and depressive complaints (T0-T1 and T0-T2). To estimate the efficacy of the intervention, Poisson regression analysis was used for the outcomes sickness absence duration and sickness absence frequency. Risk ratios were calculated for dichotomous outcomes. Linear regression analysis was used for continuous outcomes, adjusted for baseline differences. Multivariate Cox regression analysis was used to test differences in time to onset of the first sickness absence spell. Clinically meaningful changes on the BDI-II were determined by calculating the Reliable Change Index as developed by Jacobson and Truax. ${ }^{38}$ This approach is based on two components: reliable change, that is a decrease of at least 7 points; and clinically significant change, that is post-treatment score below $14 .{ }^{29} 31$ Chi-square tests were used to test frequency differences in reliable and clinically significant change.
Second, for the per-protocol analyses, outcomes were compared between those employees who received at least one treatment session and the control group.

All analyses were performed using SPSS version 15.0, Stata statistical software package 8.0 and SAS.

\section{RESULTS \\ Participants}

Figure 1 presents a flow chart of the study. Recruitment started in February 2007 and was completed in October 2007. A total of 139 employees were enrolled in the trial and randomised into the intervention group $(n=69)$ or the control group $(n=70)$. At 6 and 12 months of follow-up, questionnaire data were available for 99 and 89 participants respectively. Objective sickness absence data were available for all participants for 18 months of follow-up. The baseline characteristics of the trial population are listed in table 1. Except for BDI and BSI, baseline characteristics were comparable between the intervention and control group.

\section{Effects of the intervention on the primary outcomes sickness absence duration and depressive complaints}

Table 2 presents the results of the intention-to-treat analysis for the primary outcome measures sickness absence duration at 12 and 18 months of follow-up and depressive complaints at 6 and 12 months of follow-up. A significant difference in total sickness absence duration was found between the intervention (27.5 days) and control group (50.8 days) at 12 months of follow-up, a reduction of $46 \% \quad(p=0.017)$. The intervention group showed a non-significantly lower proportion of long-term sickness absence spells (nine of 69) compared with the control group (17 of 70$)(p=0.127)$ at 12 months of follow-up. At 18 months of follow-up, the total sickness absence duration was 45.0 days in the intervention group and 62.6 days in the control group, a reduction of $28.0 \%$. However, this result failed to reach statistical significance $(p=0.150)$. No significant difference was found in the proportion of long-term sickness absence as well $(p=0.175)$. Regarding depressive complaints, significant differences in change scores were observed for both T1-T0 $(p=0.001)$ and T2-T0 $(p=0.005)$ between the intervention and control

Table 1 Baseline characteristics of the trial population

\begin{tabular}{lrr}
\hline Variable & \multicolumn{1}{c}{$\begin{array}{l}\text { Intervention } \\
\text { group }(\mathbf{n}=\mathbf{6 9})\end{array}$} & \multicolumn{1}{c}{$\begin{array}{l}\text { Control } \\
\text { group }(\mathbf{n}=\mathbf{7 0})\end{array}$} \\
\hline Gender, male; N (\%) & $42(60.9)$ & $43(61.4)$ \\
Age (18-65); mean (SD) & $48.41(8.68)$ & $47.07(9.49)$ \\
Highest level of education; N (\%) & & \\
Low & $5(7.9)$ & $6(9.0)$ \\
Medium & $49(77.8)$ & $45(67.2)$ \\
High & $9(14.3)$ & $16(23.9)$ \\
Presence of long-term illness; N (\%)† & $39(59.1)$ & $34(51.5)$ \\
Living alone; N (\%) $\dagger$ & $12(17.4)$ & $13(18.6)$ \\
Depressive complaints (Hospital Anxiety & $10.45(2.67)$ & $9.97(2.34)$
\end{tabular}

and Depression Scale-Depression)

(0-21) ‡; mean (SD)

Depressive complaints (Beck Depression

Inventory-II) (0-63)‡; mean (SD)

Psychological distress (Brief Symptom Inventory) (0-212) $\ddagger$; mean (SD)

Score on Balansmeter (indicating risk of sickness absence); mean (SD)

Working hours/week; mean (SD)

$17.03(9.56)$

$14.84(8.11)$

$40.79(27.85)$

$35.34(25.47)$

Having an executive position; N (\%)†

$-0.5902(0.9599)$

$-0.5993(0.7562)$

*Categorical variable with $\mathrm{N}(\%)$ indicating 'yes.

†Dichotomous variable (yes/no) with $\mathrm{N}(\%)$ indicating 'yes.'

$\ddagger$ Scale range. 
Table 2 Outcomes of the intention-to-treat analysis, with objective sickness absence measured at 12 months and 18 months of follow-up and questionnaire data measured at baseline (T0), 6 months (T1) and 12 months (T2) of follow-up.

\begin{tabular}{|c|c|c|c|c|}
\hline Variable & Intervention group $(n=69)$ & Control group $(n=70)$ & $\beta, \mathrm{RR}, \mathrm{HR} \S(95 \% \mathrm{CI})$ & p Value \\
\hline \multicolumn{5}{|l|}{ Objective sickness absence } \\
\hline \multicolumn{5}{|l|}{$0-12^{*}$} \\
\hline At least one time on sick leave; $N(\%) \neq$ & $56(81.2)$ & $48(68.6)$ & $1.18(0.97$ to 1.44$)$ & 0.118 \\
\hline $\begin{array}{l}\text { Duration (calendar days); mean (SD)/ } \\
\text { median }\end{array}$ & $27.48(44.74) / 11.00$ & $50.83(75.75) / 15.00$ & $-0.62(-1.12$ to -0.11$)$ & 0.017 \\
\hline Frequency; mean (SD)/median & $2.34(1.61) / 2.00$ & $2.35(1.78) / 2.00$ & $-0.01(-0.28$ to 0.26$)$ & 0.963 \\
\hline $\begin{array}{l}\text { Time to onset of first sickness absence } \\
\text { spell (calendar days); mean (SD) }\end{array}$ & $151.38(136.99)$ & $187.37(146.42)$ & 1.35 (0.92 to 1.99$)$ & 0.129 \\
\hline \multicolumn{5}{|l|}{$0-18 \dagger$} \\
\hline At least one time on sick leave; N (\%) $\neq$ & $62(89.9)$ & $56(80.0)$ & $1.12(0.98$ to 1.29$)$ & 0.154 \\
\hline $\begin{array}{l}\text { Duration (calendar days); mean (SD)/ } \\
\text { median }\end{array}$ & $45.03(76.59) / 20.50$ & $62.57(81.89) / 25.50$ & $-0.33(-0.78$ to 0.12$)$ & 0.150 \\
\hline Frequency; mean (SD)/median & $2.97(2.09) / 2.00$ & $2.93(2.17) / 2.00$ & $0.01(-0.24$ to 0.67$)$ & 0.918 \\
\hline $\begin{array}{l}\text { Time to onset of first sickness absence } \\
\text { spell (calendar days); mean (SD) }\end{array}$ & $177.87(184.21)$ & $231.19(206.57)$ & $1.34(0.93$ to 1.93$)$ & 0.117 \\
\hline \multicolumn{5}{|c|}{ Participants with sickness absence spell(s) $>28$ calendar days; N $(\%) \ddagger$} \\
\hline $0-12^{*}$ & $9(13.0)$ & $17(24.6)$ & $0.54(0.26$ to 1.12$)$ & 0.127 \\
\hline $0-18 \dagger$ & $14(20.3)$ & $22(31.4)$ & $0.65(0.36$ to 1.16$)$ & 0.175 \\
\hline \multicolumn{5}{|c|}{ Depressive complaints according to Beck Depression Inventory-II $(0-63) \uparrow$; mean (SD) } \\
\hline Baseline TO & $17.03(9.55)$ & $14.84(8.11)$ & & \\
\hline T1 & $12.77(10.48)$ & $16.30(10.08)$ & & \\
\hline $\mathrm{T} 2$ & $12.42(9.64)$ & $16.69(11.04)$ & & \\
\hline $\mathrm{T} 1-\mathrm{TO}$ & $-4.41(7.00)$ & $0.92(7.06)$ & $-5.08(-7.91$ to -2.25$)$ & 0.001 \\
\hline T2-T0 & $-3.79(8.45)$ & $2.09(9.51)$ & $-5.40(-9.12$ to -1.68$)$ & 0.005 \\
\hline \multicolumn{5}{|c|}{ Depressive complaints according to Hospital Anxiety and Depression Scale-Depression (0-21) ; mean (SD) } \\
\hline Screening & $10.45(2.67)$ & $9.97(2.34)$ & & \\
\hline $\mathrm{T} 1$ & $7.67(4.26)$ & $8.55(3.81)$ & & \\
\hline $\mathrm{T} 2$ & $7.24(4.62)$ & $9.40(4.23)$ & & \\
\hline T1-screening & $-2.91(3.67)$ & $-1.45(3.06)$ & $-1.38(-2.74$ to -0.02$)$ & 0.046 \\
\hline T2-screening & $-3.24(4.50)$ & $-0.38(3.91)$ & $-2.62(-4.41$ to -0.83$)$ & 0.005 \\
\hline \multicolumn{5}{|c|}{ Psychological distress (Brief Symptom Inventory) (0-212) ; mean (SD) } \\
\hline Baseline & $40.79(27.85)$ & $35.34(25.47)$ & & \\
\hline $\mathrm{T} 1$ & $32.26(30.84)$ & $36.89(29.43)$ & & \\
\hline $\mathrm{T} 2$ & $32.19(33.29)$ & $42.19(33.78)$ & & \\
\hline $\mathrm{T} 1-\mathrm{T} 0$ & $-9.71(18.12)$ & $4.55(17.33)$ & $-13.88(-21.72$ to -6.04$)$ & 0.001 \\
\hline $\mathrm{T} 2-\mathrm{T} 0$ & $-9.32(25.39)$ & $6.51(15.69)$ & $-15.69(-25.11$ to -6.26$)$ & 0.001 \\
\hline
\end{tabular}

group, in favour of the intervention group. Depressive complaints decreased in the intervention group during follow-up and increased in the control group. The intervention group showed a significantly higher proportion of participants with a reliable change in depressive complaints (15 of 43) versus the control group ( 8 of 51$)$ at $6(p=0.031)$ and 12 months $(p=0.022)$ of follow-up (proportion reliable change in the intervention group 13 of 42, in the control group 5 of 45). RRR were $19.2 \%$ and $19.8 \%$, NNT were $5.2(95 \%$ CI 2.7 to 55.5$)$ and $5.0(95 \% \mathrm{CI}$ 2.7 to 32.1$)$ respectively, for 6 and 12 months of follow-up. The proportion of clinically relevant change in the intervention group was 27 of 44 versus 26 of 53 in the control group at 6 months of follow-up $(p=0.225)$. At 12 months, the clinically relevant change in the intervention group was 28 of 43 and 20 of 45 in the control group $(p=0.052)$.

\section{Effects of the intervention on secondary outcomes}

Table 2 also presents the results of the intention-to-treat analysis for the secondary outcomes. Comparable with the results on BDI-II, statistically significant differences in change scores on $\mathrm{HAD}-\mathrm{D}$ were found in favour of the intervention group, between T1-T0 and T2-T0. Significant differences were found for change scores for T1-T0 and T2-T0 on BSI as well. Again, scores decreased in the intervention group and increased in the control group. No significant differences were found between T1-T0 and T2-T0 between both groups on self-rated health and work characteristics (results not shown).

\section{Per-protocol analysis}

Table 3 presents the results of the per-protocol analyses. Sickness absence and depressive complaints were compared between the intervention group, including those employees who received at least one session, and the control group. The intervention group demonstrated a significantly lower sickness absence duration of $52.2 \%$ after 12 months $(\mathrm{p}=0.021)$ and $47.1 \%$ after 18 months $(p=0.021)$ compared with the control group. The latter result of sickness absence duration at 18 months of follow-up differs with the result of the intention-to-treat analysis, in which a nonsignificant reduction of $28.0 \%$ was found. No significant difference was found for the proportion of sickness absence spells $>28$ days at 12 months $(p=0.160)$ and 18 months $(p=0.078)$ of follow-up. Regarding depressive complaints, similar to the 
Table 3 Outcomes of the per-protocol analysis, objective sickness absence measured at 12 and 18 months of follow-up and questionnaire data measured at baseline (TO), 6 (T1) and 12 months (T2) of follow-up.

\begin{tabular}{|c|c|c|c|c|}
\hline Variable & $\begin{array}{l}\text { Intervention group, 'never started' } \\
\text { group excluded }(n=46)\end{array}$ & Control group $(n=70)$ & $\beta, \mathrm{RR}, \mathrm{HR} \S(95 \% \mathrm{CI})$ & p Value \\
\hline \multicolumn{5}{|l|}{ Objective sickness absence $0-12^{*}$} \\
\hline At least once on sick leave $(N, \%) \ddagger$ & $34(73.9)$ & $48(68.6)$ & $1.08(0.85$ to 1.36$)$ & 0.677 \\
\hline $\begin{array}{l}\text { Duration (calendar days); mean (SD)/ } \\
\text { median }\end{array}$ & $24.29(34.18) / 11.00$ & $50.83(75.75) / 15.00$ & $-0.74(-1.37$ to -0.11$)$ & 0.021 \\
\hline Frequency; mean (SD)/median & $2.18(1.47) / 2.00$ & $2.35(1.78) / 2.00$ & $-0.08(-0.39$ to 0.23$)$ & 0.621 \\
\hline $\begin{array}{l}\text { Time to onset of first sickness absence } \\
\text { spell (calendar days); mean (SD) }\end{array}$ & $165.67(143.77)$ & $187.37(146.42)$ & $1.18(0.76$ to 1.82$)$ & 0.473 \\
\hline \multicolumn{5}{|l|}{$0-18 \dagger$} \\
\hline At least one time on sick leave $(\mathrm{N}, \%) \ddagger$ & $39(84.8)$ & $56(80.0)$ & $1.06(0.89$ to 1.26$)$ & 0.625 \\
\hline $\begin{array}{l}\text { Duration (calendar days); mean (SD)/ } \\
\text { median }\end{array}$ & $33.05(51.18) / 15.00$ & $62.57(81.89) / 25.50$ & $-0.64(-1.18$ to -0.10$)$ & 0.021 \\
\hline Frequency; mean (SD)/median & $2.69(1.89) / 2.00$ & $2.93(2.17) / 2.00$ & $-0.08(-0.37$ to 0.20$)$ & 0.569 \\
\hline $\begin{array}{l}\text { Time to onset of first sickness absence } \\
\text { spell (calendar days); mean (SD) }\end{array}$ & $200.76(198.97)$ & $231.19(206.57)$ & $1.18(0.78$ to 1.77$)$ & 0.441 \\
\hline \multicolumn{5}{|c|}{ Participants with sickness absence spell $>28$ calendar days; N $(\%) \ddagger$} \\
\hline $0-12^{*}$ & $6(13.0)$ & $17(24.3)$ & $0.54(0.23$ to 1.26$)$ & 0.160 \\
\hline $0-18 \dagger$ & $7(15.2)$ & $22(31.4)$ & $0.48(0.23$ to 1.04$)$ & 0.078 \\
\hline \multicolumn{5}{|c|}{ Depressive complaints according to Beck Depression Inventory-II (0-63) ; Mean (SD) } \\
\hline Baseline TO & $18.15(9.42)$ & $14.84(8.11)$ & & \\
\hline T1 & $14.00(11.50)$ & $16.30(10.08)$ & & \\
\hline $\mathrm{T} 2$ & $12.31(10.01)$ & $16.69(11.04)$ & & \\
\hline $\mathrm{T} 1-\mathrm{T} 0$ & $-4.50(7.59)$ & $0.93(7.06)$ & $-5.02(-8.34$ to -1.70$)$ & 0.004 \\
\hline T2-T0 & $-4.66(8.76)$ & $2.09(9.51)$ & $-6.05(-10.34$ to -1.75$)$ & 0.006 \\
\hline
\end{tabular}

*Measured from baseline until 12 months of follow-up.

†Measured from baseline until 18 months of follow-up.

$\ddagger$ Dichotomous variable (no/yes) with $\mathrm{N}(\%)$ indicating 'yes.'

$\S \beta(95 \% \mathrm{CI})$ in case of continuous variable and RR (95\% CI) in case of dichotomous variable and HR in case of time to onset of first sickness absence spell.

बScale range.

results of the intention-to-treat analysis, statistically significant lower scores on BDI-II were found between T1-T0 $(p=0.004)$ and T2-T0 $(p=0.006)$ in the intervention group. HAD-D also showed significantly lower scores at T2-Screening in the intervention group, and for BSI significant differences were found between both T1-T0 and T2-T0 (results not shown).

\section{Treatment received and cointerventions}

Of the 69 employees allocated to the intervention group, 38 employees completed the intervention and returned their workbooks. The mean number of sessions was 7.5 (SD 2.5). The mean protocol adherence of the psychologists was 95\% (SD 12.6). With respect to the use of cointerventions (table 4) only a small number of employees received cointerventions specifically for depressive complaints. No significant and clinically relevant differences were found between the intervention and control group at baseline, 6 and 12 months of follow-up in their use of cointerventions.

\section{DISCUSSION}

\section{Principal findings and interpretation of outcomes}

The aim of this study was to evaluate the effect of a preventive intervention among employees identified at high risk of future long-term sickness absence and with mild to severe depressive complaints in a RCT. The preventive intervention had a substantial effect on sickness absence duration and depressive complaints in favour of the intervention group. During the years in which this study was conducted, sickness absence rates in the company under study were $3.83 \%$ (in 2007) and $3.77 \%$ (in 2008). Sickness absence rates were $13.93 \%$ in the control group and $7.53 \%$ in the intervention group over 12 months of follow-up, which indicates that indeed a high-risk group was selected.
Although sickness absence was substantially lower in the intervention group than in the control group, the sickness absence rates of the company could not be reached during the follow-up of 18 months. The proportion of long-term sickness absence spells showed no significant difference between the intervention and control group, despite a reduction of $40 \%$ as described in the power calculation. This may be explained by the decrease in sickness absence rates in The Netherlands, from approximately $6.0 \%$ in 1999 , the year in which the power calculation was conducted, to $4.3 \%$ in 2009 . Results may have failed to reach statistical significance due to the lower prevalence of sickness absence in the population. Sickness absence frequency and time to onset of the first sickness absence spell may have been influenced by the intervention as well, but no significant differences were found between the groups, which may have been because the power was too low.

Table 4 Cointerventions used 6 months before completing questionnaires $\mathrm{T} 1$ and $\mathrm{T} 2$

\begin{tabular}{|c|c|c|c|}
\hline Variable & $\begin{array}{l}\text { Intervention } \\
\text { group }(n=69)\end{array}$ & $\begin{array}{l}\text { Control } \\
\text { group }(n=70)\end{array}$ & p Value \\
\hline \multicolumn{4}{|c|}{ Cointerventions*; N (\%) } \\
\hline At T1 & $35(77.8)$ & $35(64.8)$ & 0.158 \\
\hline At T2 & $31(72.1)$ & $33(70.2)$ & 0.960 \\
\hline \multicolumn{4}{|c|}{ Receiving treatment for depressive complaints (not our intervention); N (\%) } \\
\hline At $\mathrm{T} 1$ & $2(4.4)$ & $7(13.0)$ & 0.142 \\
\hline At T2 & $5(11.6)$ & $4(8.5)$ & 0.644 \\
\hline \multicolumn{4}{|c|}{ Medication use; N (\%) } \\
\hline At T1 & $33(73.3)$ & $35(64.8)$ & 0.363 \\
\hline At T2 & $27(62.8)$ & $27(57.4)$ & 0.788 \\
\hline
\end{tabular}

*Treatment by general practitioner, occupational physician, psychologist, psychiatrist company counsellor or other. 
With regard to depressive complaints (BDI-II), substantial effects were found in the intention-to-treat analysis, again in favour of the intervention group. Scores on BDI-II increased over time in the control group and decreased in the intervention group. Participants in the intervention and control group did not differ in their use of cointerventions. Cointerventions were not likely to have influenced the results, but this could not be completely ruled out. Cointerventions might have reduced the contrast between the groups, and this might have led to an underestimation of the effects found.

Regarding the per-protocol analysis, sickness absence duration was significantly lower in the intervention group at 12 months but also at 18 months. These results indicate that when participants received at least one session, the reduction of sickness absence duration remained approximately 50\% until 18 months of follow-up. Regarding depressive complaints, similar results to the intention-to-treat analysis were found. Again, scores on BDI-II increased in the control group and decreased in the intervention group over time. Thus, these results demonstrate that even a small number of sessions seems to be effective. For the per-protocol analysis, a rather conservative approach was used, which also indicates that our results may be an underestimation.

\section{Methodological considerations}

Strengths of the study include the randomised design, the availability of a nationwide study population of employees, the objective measurement of sickness absence, the intervention for which a specific protocol was developed, the long follow-up period of 18 months and the monitoring of cointerventions.

Some considerations should be taken into account when interpreting the results of the study. During the pilot study conducted prior to the RCT, a smaller-than-expected overlap between the concepts of risk for future sickness absence and depressive complaints was found. To guarantee sufficient numbers of participants, two adjustments to the original study design were required. First, the screening questionnaire was sent to more employees than originally planned. Second, the cut-off point on the Balansmeter was adapted to a cut-off point with a higher sensitivity to improve the overlap between the concepts. The original cut-off point on the HAD-D was maintained, since this cut-off point has been used in many studies. The smaller-than-expected overlap between both concepts may be explained by differences in the background of the concepts. Risk of sickness absence has a multifactorial aetiology, which does not necessarily include health complaints.

The HAD-D was used to identify employees with mild to severe depressive complaints. To study the course of depressive complaints, the more widely used and more extensive questionnaire BDI-II was used. Our results indicate that many of those employees identified with mild to severe depressive complaints by HAD-D (48.2\%) scored in the no to minimal depressive complaints range of the $\mathrm{BDI}-\mathrm{II}$ at baseline. The mean BDI-II score was 9.77 (SD 3.35) in this category. Regardless of the relatively low score of the employees identified, scores were still in the upper part of the lowest category of BDI-II (range $0-13)$. So, a reliable and relevant change on BDI-II ( $>7$ points) could still occur.

With regard to blinding, the researcher analysed all data anonymously using personnel numbers. Participants in the RCT were not blinded, since they were aware into which group they were randomised. However, little influence on the results was expected, since no differences in the use of cointerventions were observed. Company counsellors and psychologists were partially blinded, as they were only aware of participants in the intervention group. Therefore, no influence on the contrast between the intervention- and control group was expected. Incomplete blinding may have had some influence on the outcome depressive complaints and the secondary outcomes. However, sickness absence was measured objectively and blinded for the researcher and could therefore not have influenced the results.

Only 38 employees of the 69 employees who were randomised into the intervention group received the intervention according to protocol, implying $44.9 \%$ incomplete interventions. A withdrawal rate of $35.3 \%$ was found on the questionnaires at 12 months of follow-up. Drop-outs and loss-to-follow-up in the intervention group could have affected the results. However, since objective sickness absence data were available for all 139 randomised employees, there were no consequences for this outcome. For depressive complaints, no selective attrition was found, and no differences in baseline values on BDI-II were found between respondents and non-respondents on T1 and T2 The high number of employees dropping out after consultation with the company counsellor may be explained by the fact that the focus of the RCT was on relatively mild depressive complaints and an increased risk for a future event. Many employees reported not to experience health complaints at the moment of completing the screening questionnaire and therefore may have refused participation. ${ }^{39}$

\section{Implications and future research}

This study focused on prevention of sickness absence and major depression; however prevention will never completely compensate treatment, since there will always be employees who will develop a clinical depression, who have depressive complaints but do not lose their work ability, who will go on sick leave or who do not benefit from preventive intervention. As a result, treatment remains very important.

The focus of our RCT was on employees with relatively mild depressive complaints. Within this mild level, complaints vary in severity. Our results demonstrated that 17 of the 46 employees who started participation in the intervention received fewer than seven sessions of the basic part of the intervention. From a research perspective, it was preferable to indicate a fixed number of sessions the participants should receive in the intervention, to be able to exactly define completion of the intervention. However, in practice this approach was not feasible, since it was unknown how many sessions were required for the mild level of complaints. The per-protocol analysis showed that receiving even a small number of sessions seems already effective. This may indicate that the intervention should be tailored to an employee's individual level of complaints.

The efficacy of the preventive intervention was evaluated among employees in an office work environment. Therefore, this study is not fully representative for the general working population. Nevertheless, it is believed that the intervention may be suitable for similar companies in the occupational healthcare setting, because of the occurrence of comparable kinds of complaints/problems, characterised by stress-related (mental) disorders.

When considering implementation of the preventive strategy into daily practice, employers and policymakers should weigh the effects against the costs of the intervention. Evaluation of the cost-effectiveness was not part of the study. However, based on the intention-to-treat analysis, a decrease of 555 working days of sickness absence between the intervention and control groups was calculated over 18 months of follow-up. The mean labour costs account for $€ 200$ per working day. Thus, the profits 
of reduction of sickness absence amounted to $€ 111000$. Besides benefits in terms of money due to sickness absence, it is known that depression is associated not only with absenteeism but also with presenteeism. ${ }^{40}$ The positive effect of the intervention on depressive complaints may lead to increased at-work job performance and productivity. In future research, a more extensive cost-benefit analysis should be performed including all facets of the preventive strategy.

In conclusion, the results of this study showed strong preventive effects on both long-term sickness absence and major depression. In the light of the difficult return to work in employees who are already on sick leave, this study clearly demonstrated that a new preventive intervention is a more promising approach in the prevention and reduction of sickness absence and improvement of mental health among employees.

Acknowledgements The authors thank A Arntz and M Huibers (Maastricht University), T Bouman (University Medical Center Groningen) and A van den Hout (Academic Community Health Centre Maastricht), experts in the field of psychology, for development of the protocol and workbooks for the preventive intervention and training of the participating psychologists. The authors also thank $D$ de Bruyn, $S$ Dijkstra, H Kalter, W ten Haaf and P Batting, company counsellors from Occupational Health Services 'Beter,' for performing the consultations. The authors also thank I Pos, director of Cenzo BV, for coordination of execution of the intervention, and J Biemans, S Decoz, J Haasnoot, A Janssen, A Kuipers, G Langenhuizen, M Ooms, G Oppewal, R Verhoog and M Udenhout, psychologists from Cenzo BV, for providing the psychological intervention. The authors thank $J$ Slangen and P Brouns (Maastricht University), B Couwenberg and M Binsbergen (Occupational Health Services 'Beter'), for their contribution to data management.

Funding This study was financially supported by The Netherlands Organisation for Health Research and Development (Zon Mw), grant no 62200024, by CAPHRI School for Public Health and Primary Care, Maastricht, The Netherlands and by the Occupational Health Services 'Beter' (ABN AMRO Arbo Services), Amsterdam, The Netherlands.

\section{Competing interests None.}

Ethics approval Ethics approval was provided by the Medical and Ethical Committee of Maastricht University (MEC 06-3-018), Maastricht, The Netherlands.

Provenance and peer review Not commissioned; externally peer reviewed.

\section{REFERENCES}

1. Bultmann U, Kant I, Kasl SV, et al. Fatigue and psychological distress in the working population: psychometrics, prevalence, and correlates. J Psychosom Res 2002; 52:445-52.

2. Kant IJ, Bultmann U, Schroer KA, et al. An epidemiological approach to study fatigue in the working population: the Maastricht Cohort Study. Occup Environ Med 2003;60(Suppl 1):i32-9.

3. World Health Organization. World Health Report, 2000. Geneva: World Health Organization, 2000

4. Andrea H, Bultmann U, Beurskens AJ, et al. Anxiety and depression in the working population using the HAD Scale-psychometrics, prevalence and relationships with psychosocial work characteristics. Soc Psychiatry Psychiatr Epidemiol 2004;39:637-46.

5. Kant I, Jansen NW, van Amelsvoort LG, et al. Structured early consultation with the occupational physician reduces sickness absence among office workers at high risk for long-term sickness absence: a randomized controlled trial. J Occup Rehabil 2008;18:79-86.

6. Laitinen-Krispijn S, Bijl RV. Mental disorders and employee sickness absence: the NEMESIS study. Netherlands Mental Health Survey and Incidence Study. Soc Psychiatry Psychiatr Epidemiol 2000;35:71-7.

7. Lexis MA, Jansen NW, van Amelsvoort LG, et al. Depressive complaints as a predictor of sickness absence among the working population. J Occup Environ Med 2009:51:887-95.

8. Stansfeld S, Feeney A, Head J, et al. Sickness absence for psychiatric illness: the Whitehall II Study. Soc Sci Med 1995;40:189-97.

9. Marmot M, Feeney A, Shipley M, et al. Sickness absence as a measure of health status and functioning: from the UK Whitehall II study. J Epidemiol Community Health 1995;49:124-30.

10. Blank L, Peters J, Pickvance $S$, et al. A systematic review of the factors which predict return to work for people suffering episodes of poor mental health. J Occup Rehabil 2008;18:27-34.

11. Brouwers EP, Tiemens BG, Terluin B, et al. Effectiveness of an intervention to reduce sickness absence in patients with emotional distress or minor mental disorders: a randomized controlled effectiveness trial. Gen Hosp Psychiatry 2006;28:223-9.

12. Melchior M, Ferrie JE, Alexanderson K, et al. Using sickness absence records to predict future depression in a working population: prospective findings from the GAZEL cohort. Am J Public Health 2009;99:1417-22.

13. Vahtera J, Westerlund $\mathrm{H}$, Ferrie JE, et al. All-cause and diagnosis-specific sickness absence as a predictor of sustained sub-optimal health: a 14-year follow-up in the GAZEL cohort. J Epidemiol Community Health 2010;64:311-17.

14. Kant IJ, Jansen NW, van Amelsvoort LG, et al. Screening questionnaire Balansmeter proved successful in predicting future long-term sickness absence in office workers. J Clin Epidemiol 2009;62:408-14.

15. Gloaguen V, Cottraux J, Cucherat $\mathrm{M}$, et al. A meta-analysis of the effects of cognitive therapy in depressed patients. J Affect Disord 1998;49:59-72.

16. Wampold BE, Minami T, Baskin TW, et al. A meta-(re)analysis of the effects of cognitive therapy versus 'other therapies' for depression. J Affect Disord 2002;68:159-65.

17. Beck AT. The current state of cognitive therapy: a 40-year retrospective. Arch Gen Psychiatry 2005;62:953-9.

18. Hollon SD, Stewart MO, Strunk D. Enduring effects for cognitive behavior therapy in the treatment of depression and anxiety. Annu Rev Psychol 2006; 57:285-315.

19. Bell AC, D'Zurilla TJ. Problem-solving therapy for depression: a meta-analysis. Clin Psychol Rev 2009;29:348-53.

20. Mynors-Wallis LM, Gath DH, Day A, et al. Randomised controlled trial of problem solving treatment, antidepressant medication, and combined treatment for major depression in primary care. BMJ 2000;320:26-30.

21. McCrone $\mathbf{P}$, Knapp M, Proudfoot J, et al. Cost-effectiveness of computerised cognitive-behavioural therapy for anxiety and depression in primary care: randomised controlled trial. Br J Psychiatry 2004;185:55-62

22. Van den Hout JH, Vlaeyen JW, Heuts PH, et al. Secondary prevention of workrelated disability in nonspecific low back pain: does problem-solving therapy help? A randomized clinical trial. Clin J Pain 2003;19:87-96.

23. Bouman TK. Draaiboek 'omgaan met ziektevrees,' probleem oplossen. [Treatment manual 'coping with health anxiety,' Problem solving] Unpublished internal document. Groningen: University of Groningen, Department Clinical Psychology, 2000.

24. Kole-Snijders AM, Geurts SM, van den Hout JH, et al. Probleemoplossende Vaardigheidstraining: Een Groeps- En Individueel Programma. Handleiding Voor Therapeuten En Werkboek Voor Deelnemers. [Problem Solving Skills Training: a Group and Individual Program. Manual for Therapists and Workbook for Clients]. Amsterdam: Boom Test Publishers, 2006.

25. Nezu AM. Cognitive appraisal of problem solving effectiveness: relation to depression and depressive symptoms. J Clin Psychol 1986;42:42-8.

26. Nezu AM, Nezu CM, Friedman SH, et al. A Problem Solving Approach. Helping Cancer Patients to Cope. Washington, DC: American Psychological Association, 1998.

27. Snaith RP. The Hospital Anxiety and Depression Scale. Health Oual Life Outcomes 2003; 1:29.

28. Zigmond AS, Snaith RP. The Hospital Anxiety and Depression Scale. Acta Psychiatr Scand 1983;67:361-70.

29. Beck AT, Steer RA, Brown GK. Beck Depression Inventory Second Edition-Manual San Antonio, TX: The Psychological Corporation, 1996.

30. Arnau RC, Meagher MW, Norris MP, et al. Psychometric evaluation of the Beck Depression Inventory-II with primary care medical patients. Health Psychol 2001;20:112-19.

31. Van der Does AJ. De Nederlandse Versie Van De Beck Depression Inventory-Second Edition (BDI-II-NL): Handleiding (in Dutch) [The Dutch Version of the Beck Depression Inventory - Second Edition (BDI-II-NL): A Manual]. San Antonio, TX: The Psychological Corporation, 2002.

32. Ware JE, Sherbourne CD. The MOS 36-item short-form health survey (SF-36). I. Conceptual framework and item selection. Med Care 1992;30:473-83.

33. Aaronson NK, Muller M, Cohen PD, et al. Translation, validation, and norming of the Dutch language version of the SF-36 Health Survey in community and chronic disease populations. J Clin Epidemiol 1998;51:1055-68.

34. Derogatis LR. The Brief Symptom Inventory. Baltimore, MD: Clinical Psychometric Research, 1975.

35. Arrindell WA, Ettema JH. SCL-90: Herziene Handleiding Bij Een Multidimensionele Psychopathologie-Indicator. [SCL-90: Revised Manual for a Multidimensional Indicator of Psychopathology]. Lisse, The Netherlands: Swets \& Zeitlinger, 2003.

36. Karasek RA. Job Content Questionnaire and User's Guide. Los Angeles: University of Southern California: Department of Industrial and Systems Engineering, 1985.

37. Van Veldhoven M, Meijmen T. Het Meten Van Psychosociale Arbeidsbelasting Met Een Vragenlijst: De Vragenlijst Beleving En Beoordeling Van De Arbeid (VBBA) [Questionnaire on the Experience and Evaluation of Work]. Amsterdam: NIA, 1994.

38. Jacobson NS, Truax P. Clinical significance: a statistical approach to defining meaningful change in psychotherapy research. J Consult Clin Psychol 1991;59:12-19.

39. Lexis MA, Jansen NW, Stevens FC, et al. Experience of health complaints and help seeking behavior in employees screened for depressive complaints and risk of future sickness absence. J Occup Rehabil 2010;20(4):537-46.

40. Lerner D, Adler DA, Rogers WH, et al. Work performance of employees with depression: the impact of work stressors. Am J Health Promot 2010;24:205-13. 


\section{Prevention of long-term sickness absence} and major depression in high-risk employees: a randomised controlled trial

Monique A S Lexis, Nicole W H Jansen, Marcus J H Huibers, et al.

Occup Environ Med 2011 68: 400-407 originally published online October 5, 2010

doi: 10.1136/oem.2010.057877

Updated information and services can be found at:

http://oem.bmj.com/content/68/6/400.full.html

\begin{tabular}{cl}
\hline These include: \\
References & $\begin{array}{l}\text { This article cites } 29 \text { articles, } 5 \text { of which can be accessed free at: } \\
\text { http://oem.bmj.com/content/68/6/400.full.html\#ref-list-1 }\end{array}$ \\
$\begin{array}{c}\text { Email alerting } \\
\text { service }\end{array}$ & $\begin{array}{l}\text { Receive free email alerts when new articles cite this article. Sign up in } \\
\text { the box at the top right corner of the online article. }\end{array}$ \\
\hline
\end{tabular}

Notes

To request permissions go to:

http://group.bmj.com/group/rights-licensing/permissions

To order reprints go to:

http://journals.bmj.com/cgi/reprintform

To subscribe to BMJ go to:

http://group.bmj.com/subscribe/ 